\title{
Behavioural and biochemical effects of acute central metabolic inhibition
}

Citation for published version (APA):

Blokland, A., Bothmer, J., Honig, W., \& Jolles, J. (1993). Behavioural and biochemical effects of acute central metabolic inhibition: Effects of acetyl-I-carnitine. European Journal of Pharmacology, 235(2-3), 275-281. https://doi.org/10.1016/0014-2999(93)90146-9

Document status and date:

Published: 01/01/1993

DOI:

10.1016/0014-2999(93)90146-9

Document Version:

Publisher's PDF, also known as Version of record

\section{Please check the document version of this publication:}

- A submitted manuscript is the version of the article upon submission and before peer-review. There can be important differences between the submitted version and the official published version of record.

People interested in the research are advised to contact the author for the final version of the publication, or visit the DOI to the publisher's website.

- The final author version and the galley proof are versions of the publication after peer review.

- The final published version features the final layout of the paper including the volume, issue and page numbers.

Link to publication

\footnotetext{
General rights rights.

- You may freely distribute the URL identifying the publication in the public portal. please follow below link for the End User Agreement:

www.umlib.nl/taverne-license

Take down policy

If you believe that this document breaches copyright please contact us at:

repository@maastrichtuniversity.nl

providing details and we will investigate your claim.
}

Copyright and moral rights for the publications made accessible in the public portal are retained by the authors and/or other copyright owners and it is a condition of accessing publications that users recognise and abide by the legal requirements associated with these

- Users may download and print one copy of any publication from the public portal for the purpose of private study or research.

- You may not further distribute the material or use it for any profit-making activity or commercial gain

If the publication is distributed under the terms of Article $25 \mathrm{fa}$ of the Dutch Copyright Act, indicated by the "Taverne" license above, 


\title{
Behavioural and biochemical effects of acute central metabolic inhibition: effects of acetyl-l-carnitine
}

\author{
Arjan Blokland, John Bothmer, Wiel Honig and Jellemer Jolles \\ Department of Neuropsychology and Psychobiology, Unitersity of Limburg, P.O. Box 616, NL-6200 MD Maastricht, Netherlands
}

Received 19 October 1992, revised MS received 25 January 1993, accepted 9 February 1993

\begin{abstract}
In the present study we evaluated a new method to assess the behavioural and biochemical effects of a brief period of acute hypoxia in the brain. In this method, cyanide is injected into the lateral ventricles. Spatial navigation performance in a Morris task was found to be impaired 1 and $5 \mathrm{~min}$ after an i.c.v. injection of $5.0 \mu \mathrm{g}$ cyanide but not after $2.5 \mu \mathrm{g}$ cyanide. Increased rate of phosphatidic acid formation, reflecting increased phospholipase $\mathrm{C}$ activity, were observed after injection of $5.0 \mu \mathrm{g}$ cyanide, indicating that energy-dependent phosphoinositide metabolism was affected. Chronic trcatment with acetyl-l-carnitine attenuated the cyanide-induced behavioural deficit, but had no effect on energy-dependent phophoinositide metabolism. The results suggest that, in this model, acetyl-1-carnitine may act via free fatty acid metabolism, by increasing the reservoir of activated acyl groups which are involved in the reacylation of membranc phospholipids.
\end{abstract}

Actyl-l-carnitinc; Histotoxic hypoxia; Cyanide; Spatial learning; Phosphoinositide metabolism

\section{Introduction}

There are many substances and methods which can influence brain function by changing biochemical processes involved in the energy metabolism of the brain (Auer et al., 1984; Baughman et al., 1990; Crane et al., 1978; De Ryck, 1990; Hoyer and Krier, 1986; MacMillan, 1989). Models in which the energy status of the brain is affected are used to evaluate drugs which are thought to have neuroprotective properties. These drugs reverse the development of abnormalities and/or behavioural deficits after a period of metabolic inhibition. However, these models do not allow interpretation of the acute behavioural effects of central metabolic inhibition, as the methods used to affect the energy metabolism of the brain also affect peripheral systems. Consequently, the behavioural effects observed can be explained by both central and peripheral mechanisms. For instance, Gibson and co-workers (1983) evaluated the behavioural effects of nitrite-induced hypoxia; however, interpretation of the behavioural data in terms of central effects was complicated by a nitrite-induced decrease in motor function

Correspondence to: J. Bothmer, Department of Neuropsychology and Psychobiology, University of Limburg, P.O. Box 616, NL-6200 MD Maastricht, Netherlands. Tel. (31) 43881041 , fax (31) 436710 96.
(Behroozi et al., 1972). To date, the acute effects of central anoxia/hypoxia have only been assessed in pathological or biochemical studies in which neuronal damage or biochemical markers were evaluated, respectively (Auer et al., 1984; Peruche et al., 1990).

In the present study we developed a method by which behaviour (escape performance in a Morris water task) can be assessed during a period of acute metabolic inhibition without peripheral systems being affected. Cyanide $(\mathrm{NaCN})$ is injected directly into the lateral ventricles of rats and a well-learnt behaviour is monitored during the period that cyanide has its effect on biochemical processes in the brain. We injected cyanide into the lateral ventricles so that cyanide would probably affect hippocampal function, which is known to be critically involved in the performance of the Morris task (Morris et al., 1990). Cyanide blocks the use of $\mathrm{O}_{2}$ by mitochondria and consequently induces hypoxia, i.e., histotoxic hypoxia (MacMillan, 1989). Cyanide does not cause neuronal damage per se (Brierly et al., 1976), and low doses of cyanide are converted within minutes by mitochondrial sulphur transferase into non-toxic sulphur cyanide (Hathway, 1984).

To evaluate the neurochemical effects of treatment with cyanide, we assessed three steps in the metabolism of phosphoinositides, which are known to be highly dependent on the energy state of neurons. In addition, the pathways of phosphoinositide metabolism are po- 
tential targets for neurotoxic agents (Costa, 1990). Phosphoinositide metabolism is essential for cell functioning as it is involved in neurochemical processes related to neurotransmission (Abdel-Latif, 1986; Berridge, 1987). In these processes, phosphatidylinositol 4,5-biphosphate ( $\mathrm{PIP}_{2}$ ) is hydrolysed by phospholipase $C$ into the second messengers, inositol triphosphate and diacylglycerol (Akhtar and Abdel-Latif, 1980), followed by rapid phosphorylation of diacylglycerol into phosphatidic acid. The latter phosphorylation reaction and the two-step phosphorylation of phosphatidylinositol, by which $\mathrm{PIP}_{2}$ is synthesized, take place on the plasma membrane and are highly energy dependent.

Acctyl-1-carnitine, a nootropic drug, has been reported to improve cognitive function in aged rats (Barnes et al., 1990; Caprioli et al., 1990; Ghirardi et al., 1988). Biochemically, acetyl-l-carnitine acts as a carricr of fatty acids across the inner mitochondrial membrane for their subsequent $\beta$-oxidation (Fritz, 1963). It has been found that acetyl-l-carnitine increases the metabolic rate of mitochondria, improving the mitochondrial utilization of oxygen (Bellei et al., 1989; Siliprandi et al., 1965). Acetyl-l-carnitine also enhances the utilization of alternative energy sources (Aureli et al., 1990), and may thereby attenuate the modifications of neuronal membranes associated with aging (Schoeder, 1984). Gibson and Peterson (1981) reported that the age-related decrease in glucose utilization may cause a decrease in oxidative metabolism and in the release and synthesis of acetylcholine. Since acetyl-l-carnitine may enhance the utilization of mitochondrial oxygen and alternative energy sources (Aureli et al., 1990), acetyl-l-carnitine could compensate for the decrease in glucose utilization that occurs during aging and consequently preserve neuronal function. The assumed energy-enhancing properties of acetyl-Icarnitine can be tested in a model in which the energy status of the brain is lowered experimentally.

In this study we evaluated the effects of an i.c.v. injection of cyanide on escape behaviour in the Morris task and on phosphoinositide metabolism. We hypothesized that chronic treatment with acetyl-I-carnitine would enhance the availability of alternative energy sources in neurons during hypoxia and consequently attenuate the effects of cyanide on behaviour and neuronal function.

\section{Materials and methods}

\subsection{Animals}

We used male Lewis rats from two shipments. The first shipment consisted of 15 3-month-old rats which were divided into two groups at random (control, $\mathrm{n}=7$; ALCAR, $\mathrm{n}=8$ ). The second shipment consisted of 12 3-month-old rats which were also divided into two groups at random (control, $n=6$; ALCAR, $n=6$ ). All rats were housed individually in standard Makrolon cages on sawdust bedding in an air-conditioned room (about $20^{\circ} \mathrm{C}$ ). They were kept under a $12 / 12 \mathrm{~h}$ lightdark cycle (lights on from 9:00 to 21:00).

\subsection{Treatment}

Acetyl-l-carnitine treatment was started two weeks before the rats acquired the Morris task. The ALCAR group was given $75 \mathrm{mg}$ acetyl-l-carnitine/ $\mathrm{kg}$ per day; the drug was dissolved in a $0.1 \%$ solution of saccharine (approximately $10 \mathrm{ml}$ ). The control group received a comparable amount $(10 \mathrm{ml})$ of saccharine solution. The solution was given in the morning in drinking tubes next to the standard drinking water. All rats drank the solution within $10 \mathrm{~min}$.

One week after the start of the acetyl-l-carnitine treatment, the rats were anaesthetized with pentobarbital $(60 \mathrm{mg} / \mathrm{kg}$ i.p.) and bilateral stainless steel cannulas (outer and inner diameter 0.65 and $0.30 \mathrm{~mm}$, respectively) were implanted above the lateral ventricles. The cannulas were fixed to the skull with acrylic dental cement (Paladur). The coordinates for injection were: $-0.08 \mathrm{~mm}$ anterior, $1.5 \mathrm{~mm}$ lateral and $-3.8 \mathrm{~mm}$ ventral from the bregma (Paxinos and Watson, 1986).

\subsection{Behavioural procedures}

\subsubsection{Spatial discrimination learning}

One week after surgery, the rats were trained on the standard Morris spatial navigation task (Morris, 1981) in a black water-tank (diameter of $1.22 \mathrm{~m}$ ). The rats were started from four different, randomly chosen, start positions and trained to find an invisible platform (diameter $11 \mathrm{~cm}$ ) that was at a fixed position in the water tank, $1 \mathrm{~cm}$ below the surface of the water. The temperature of the water was $20-22^{\circ} \mathrm{C}$. A trial lasted until a rat had found the platform or until $60 \mathrm{~s}$ had elapsed. If a rat did not find the platform within $60 \mathrm{~s}$, it was placed on the platform for $3 \mathrm{~s}$ and then removed from the water tank. On the first day the rats were given four trials. The rats were given eight trials on consecutive days until the rats had attained an asymptotic performance.

\subsubsection{Effects of NaCN injections}

After the rats had attained an asymptotic performance, the effects of $\mathrm{NaCN}$ injections were evaluated. On day one, the rats received four trials and were then injected with cyanide $(2.5 \mu \mathrm{g} / 2.5 \mu \mathrm{l}$ per injection site). The rats were given four additional trials, $1,5,10$ and $15 \mathrm{~min}$ after the cyanide injection. The four possible 
start positions were balanced per group during each post-injection trial. On day three, the rats underwent the same procedure as on day one, but now a dose of $5.0 \mu \mathrm{g}$ cyanide $/ 2.5 \mu \mathrm{l}$ per injection site was administered. The same procedure was repeated one week later for both doses.

\subsection{Biochemical procedures}

\subsubsection{Treatment}

Twelve animals were randomly selected from the control and ALCAR groups (three from each shipment) and divided into four groups: control $(n=6)$, control/cyanide $(n=6)$, ALCAR $(n=6)$ and ALCAR/cyanide $(n=6)$. The two cyanide-treated groups received an injection of cyanide $(5 \mu \mathrm{g})$ as described for the behavioural experiment. The control groups received an injection of saline. The rats were decapitated $1 \mathrm{~min}$ after the injection.

\subsubsection{Brain dissection}

After decapitation, the head was immediatly immersed in liquid nitrogen for $8 \mathrm{~s}$. All subsequent operations were performed at $0-4^{\circ} \mathrm{C}$. The brain was taken out of the skull and the hippocampus was rapidly dissected bilaterally.

\subsubsection{Subcellular fractionation}

Tissue from individual rats was homogenized in homogenization medium ( $0.32 \mathrm{M}$ sucrose, $1 \mathrm{mM}$ EDTA, $10 \mathrm{mM}$ Tris- $\mathrm{HCl} \mathrm{pH} \mathrm{7.4)} \mathrm{in} \mathrm{a} \mathrm{total} \mathrm{volume} 10$ times the hippocampus tissue volume by 10 up-and-down strokes of a Potter-Elvehjem Teflon-glass homogenizer. The homogenate was centrifuged for $10 \mathrm{~min}$ at $1000 \times g$. After centrifugation of the supernatant at $10000 \times g$ for $10 \mathrm{~min}$, the resulting crude mitochondrial-synaptosomal pellet $\left(\mathrm{P}_{2}\right)$ was subjected to osmotic lysis by resuspending the pellet in 10 volumes aqua bidest and stirring it for $20 \mathrm{~min}$ at $4^{\circ} \mathrm{C}$. This suspension was centrifuged for $20 \mathrm{~min}$ at $10000 \times g$ to remove unlysed structures. The $10000 \times g$ supernatant of the lysed $P_{2}$ fraction was taken as the enzyme/endogenous substrate fraction. This fraction was frozen in 1-ml aliquots and stored at $-80^{\circ} \mathrm{C}$. There is no decline in enzyme activity after at least 1 month of storage (Bothmer et al., 1990).

2.4.4. Endogenous phosphatidylinositol, phosphatidylinositol monophosphate and diacylglycerol phosphorylation assays

Endogenous phosphorylating activity was assayed under the following conditions: $7.5 \mu \mathrm{M}$ ATP $2-3 \mu \mathrm{Ci}$ $\left[\gamma_{-}{ }^{32} \mathrm{P}\right] \mathrm{ATP}$ (approximately $3000 \mathrm{Ci} / \mathrm{mmol}$, Amersham U.K.), $50 \mathrm{mM} \mathrm{Na-acetate,} 10 \mathrm{mM} \mathrm{Mg-acetate,} \mathrm{pH} 6.5$ and $15 \mu \mathrm{l}$ enzyme fraction (10 $\mu \mathrm{g}$ protein) in a final volume of $25 \mu \mathrm{l}$ at $30^{\circ} \mathrm{C}$ (Bothmer et al., 1990). The samples were pre-incubated for $5 \mathrm{~min}$ and the incuba- tion was stopped after $10 \mathrm{~s}$ by the addition of $2 \mathrm{ml}$ ice-cold chloroform:methanol: $12 \mathrm{~N} \mathrm{HCl}$ (200:100: 0.75 , by volume).

2.4.5. Lipid extraction, thin-layer chromatography and determination of radioactivity

Lipid extraction and thin-layer chromatography (TLC) were performed as described by Jolles et al. (1981). ${ }^{32} \mathrm{P}$ incorporation into phosphatidylinositol monophosphate (PIP), $\mathrm{PIP}_{2}$ and phosphatidic acid was determined by liquid scintillation counting. Two hundred microlitres of water was added to the scraped silica portions, followed by $3.8 \mathrm{ml}$ of scintillation fluid. (Ready Safe, Beckman.) Radioactivity was counted in a scintillation spectrometer (Beckman LS 1801) with an efficiency of $100 \%$.

\subsection{Statistical analysis}

\subsubsection{Shipment effects}

Shipment effects for young subjects were analysed in a two-factorial analysis of variance (shipment and group). The behavioural measures for animals from both shipments were the same (for acquisition training and cyanide sessions: all $P$ values $>0.10$ for $F$ values involving main effect and interactions with shipment). Thus the second shipment can be considered as a duplicate of the first one, and therefore data from both shipments were pooled.

\subsubsection{Spatial discrimination leaming}

Escape latencies were analysed per trial block of four trials. Differences in escape performance over trial blocks were analysed in a two-factorial (treatment and trial block) analysis of variance with repeated measures over trial blocks.

\subsubsection{Effects of cyanide injections.}

The mean escape latencies of the preinjection trials were averaged and taken as baseline performance for each rat. In order to evaluate whether cyanide treatment affected the performance of the rats, the escape latency during the trials after the animals had received cyanide was compared with the baseline latency by using $t$-statistics. The mean escape latency of the sessions 1,5 and $10 \mathrm{~min}$ after injection was calculated for each dose of cyanide. For each dose of cyanide, the effects of acetyl-l-carnitine treatment on escape latency 1,5 and $10 \mathrm{~min}$ after the cyanide injections were also analysed in a two-factorial (treatment and minutes) analysis of variance with repeated measures over time (min).

\subsubsection{Effects of cyanide and acetyl-l-carnitine on phos- phoinositide metabolism}

The effects of cyanide and acetyl-1-carnitine on phosphoinositide metabolism were evaluated in a two- 
factorial (cyanide and acetyl-1-carnitine) analysis of variance. The performance of one control rat from the first shipment was not affected by cyanide injections, and data from this rat were excluded from the statistical analysis. The lack of effect is suggestive of an incorrect cannula placement.

\section{Results}

\subsection{Spatial discrimination learning}

Chronic treatment with ALCAR did not affect spatial discrimination learning ( $F$ values $<1$, n.s.).

\subsection{Effects of NaCN injections}

\subsubsection{Spatial discrimination performance}

The acetyl-1-carnitine-treated rats did not differ from the control rats ( $t$ values $<1.7$, n.s.) in the four trials given before the injection of cyanide.

\subsubsection{Dose $2.5 \mu \mathrm{g}$}

The performance of the rats was not affected after injection of $2.5 \mu \mathrm{g}$ cyanide. ( $\mathrm{t}$ values $<1.9$, n.s.) and did not change during subsequent trials (minutes effect: $F(2,48)<1$, n.s.; see fig. 1). There was only weak statistical evidence to indicate that the performance of the control rats deviated from baseline performance

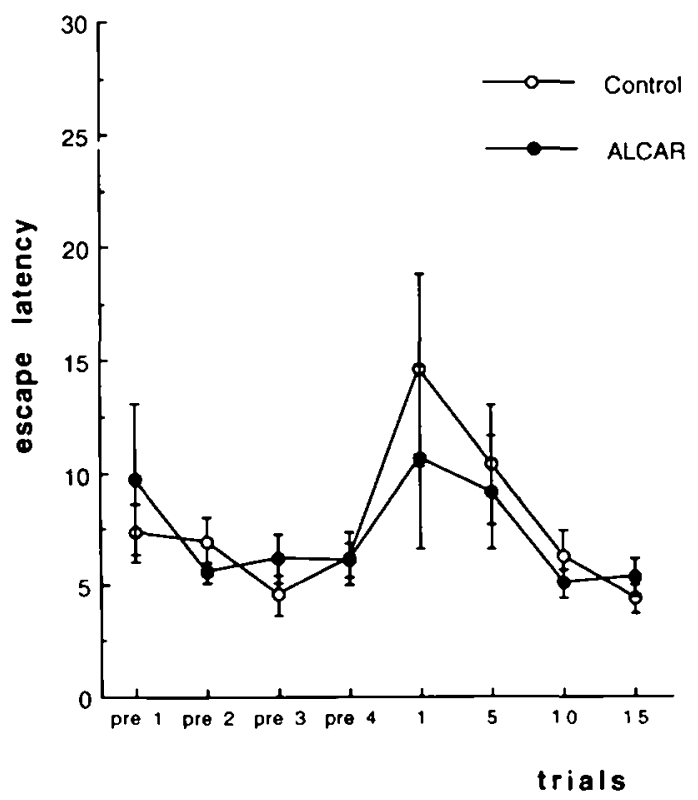

Fig. 1. Mean escape latency (in $s \pm$ S.E.M.) of control and acetyl-1carnitine-treated rats during the four pre- and post-injection (cyanide, $2.5 \mu \mathrm{g})$ trials $(1,5,10$ and $15 \mathrm{~min})$ in the Morris water escape task.

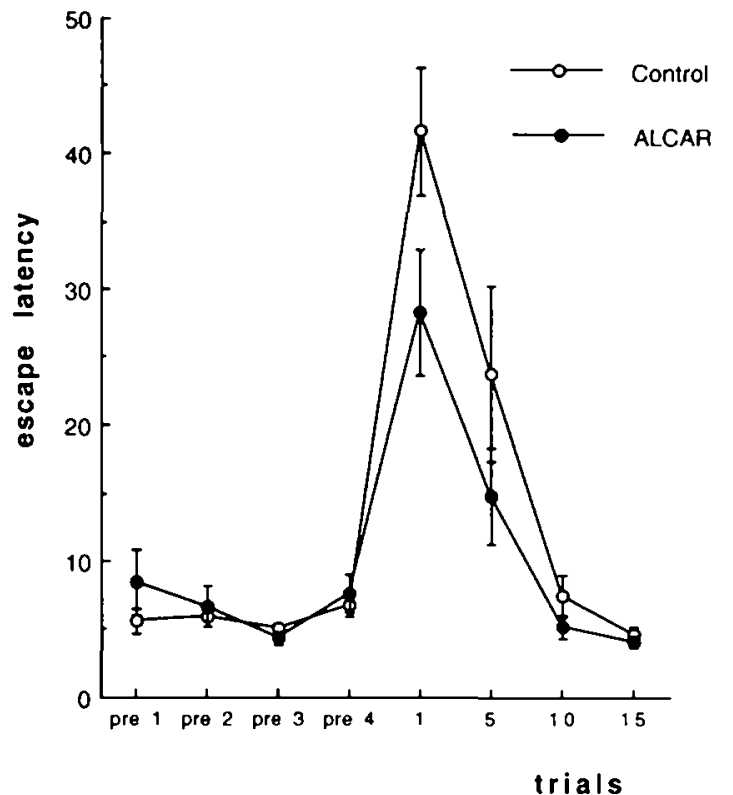

Fig. 2. Mean escape latency (in $s \pm$ S.E.M.) of control and acetyl-1carnitine-treated rats during the four pre- and post-injection (cyanide. $5.0 \mu \mathrm{g})$ trials $(1,5,10$ and $15 \mathrm{~min})$ in the Morris water escape task.

during the first trial, i.e., 1 min after injection $(\mathrm{t}(11)=$ $1.94,0.10>\mathrm{P}>0.05$ ).

\subsubsection{Dose $5.0 \mu \mathrm{g}$}

After $5.0 \mu \mathrm{g}$ cyanide, the escape latencies of the control and acetyl-I-carnitine-treated rats deviated from baseline performance during the first two trials after injection, i.e., 1 and $5 \mathrm{~min}$ after cyanide injection ( values $>2.27, \mathrm{P}<0.05$; see fig. 2). During the first trial, $1 \mathrm{~min}$ after injection, the increase in escape latency of the rats treated with acetyl-1-carnitine was less than that of the control rats $(\mathrm{t}(24)=2.16, \mathrm{p}<0.05)$. The escape latency decreased during the first three trials after the injection (minute effect: $F(2,48)=8.09$, $P<0.01$ ). The escape latency of the control rats during these trials was higher than the escape latency of the acetyl-1-carnitine-treated rats (general mean: $F(1,24)=$ 5.34, $\mathrm{P}<0.05$ ).

\subsection{Phosphoinositide metabolism}

The effects of cyanide injection (dose $5.0 \mu \mathrm{g}$ ) in vivo on phospholipid phosphorylation activities in vitro with endogeneous phosphatidylinositol, PIP and diacylglycerol as substrate are shown in fig. 3. The rate of phosphatidic acid formation was $30 \%$ higher in the cyanide-treated rats than in the rats injected with saline (cyanide effect: $F(1,20)=16.36, P<0.01$ ). The rates of $P I P$ and PIP $_{2}$ formation were not affected (F values $<1$, n.s.). Chronic treatment with acetyl-l-carnitine did not 

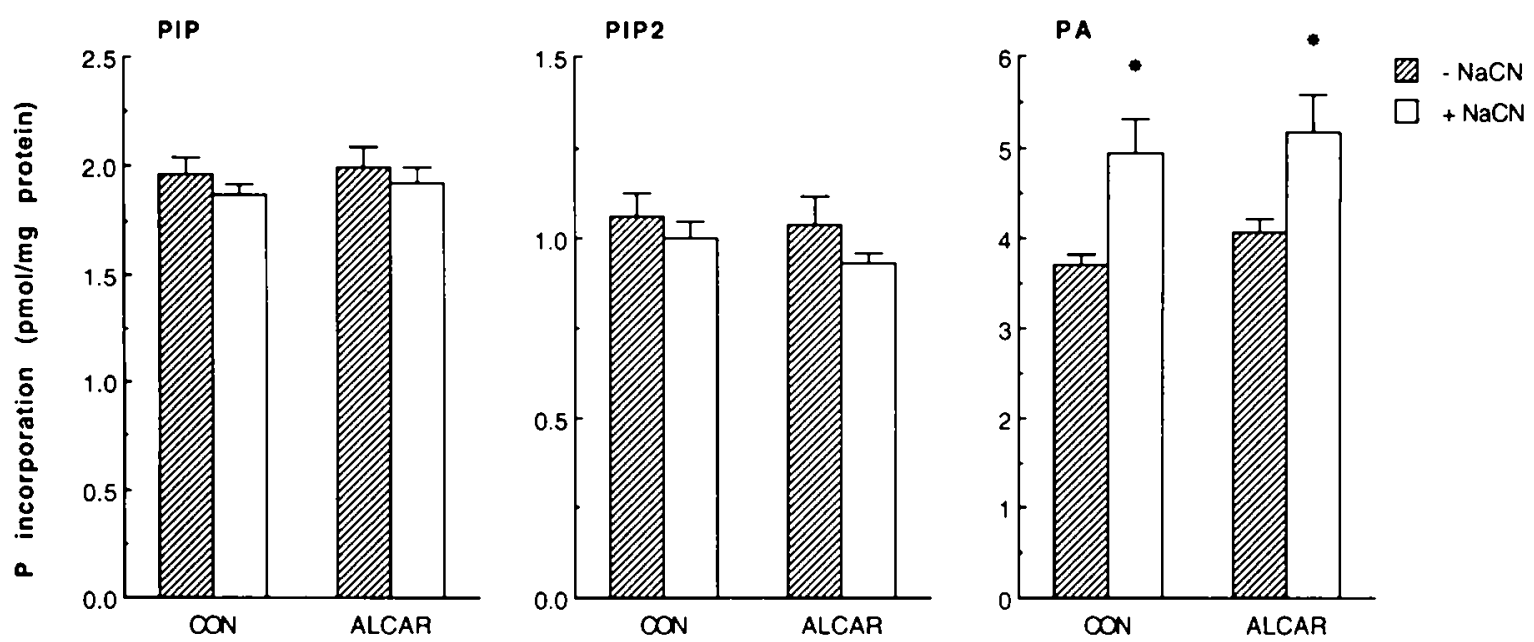

Fig. 3. Effect of i.c.y. cyanide injection $(5 \mu \mathrm{g})$ on phosphate incorporation into phosphatidylinositol phosphate (PIP), phosphatidylinositol bisphosphate (PIP2) and phosphatidic acid (PA) in a lysed $P_{2}$ fraction prepared from the hippocampus of control and acetyl-1-carnitine-treated rats.

affect the cyanide-induced change in phosphatidic acid formation (acetyl-I-carnitine effect: $F(1,20)=1.06$, n.s.).

\section{Discussion}

The performance of the rats in the Morris water task was not consistently affected after an i.c.v. injection of $2.5 \mu \mathrm{g}$ cyanide. Apparently, this dose of cyanide was too low to affect spatial navigation behaviour in rats. However, a dose of $5.0 \mu \mathrm{g}$ cyanide disrupted the performance of the rats 1 and 5 min after injection. It has been reported that if sulphur transferase is present in adequate amounts, cyanide is detoxified in approximately 15 min (Hathway, 1984). The duration of the behavioural effects of cyanide in the present study was thus comparable to the duration of the metabolic breakdown of the substance.

In a study in which the effects of a systemic injection of cyanide were evaluated in a swimming task with guinea-pigs, it was suggested that cyanide could affect cognitive function (D’Mello, 1986). This suggestion is supported by the finding that the brain is the primary target for cyanide (Way, 1984). In the present experiment we injected cyanide directly into the ventricles. It is well known that the hippocampus is a target structure for drugs that are injected i.c.v. Since disruption of hippocampal function is known to result in navigational impairments in the Morris task (Morris et al., 1990), we tentatively conclude that the cyanide-induced inhibition of metabolism caused the navigational impairment.

We measured three energy-dependent steps in the metabolism of phosphoinositides as a neurochemical parameter for cell functioning after cyanide (dose 5.0 $\mu \mathrm{g})$ treatment. Acute (1 min) cyanide-induced metabol- ic inhibition resulted in an increased rate of phosphatidic acid formation in vitro, which probably reflects an increased phospholipase $\mathrm{C}$ activity in vivo. The contents of PIP and PIP $_{2}$ decrease rapidly within a few minutes of death, followed by an increase in the content of diacylglycerol (Ikeda et al., 1986; Abe et al., 1987). Phospholipase $C$ is responsible for the hydrolysis of polyphosphoinositides, resulting in the release of inositol phosphates and diacylglycerol, the latter being a substrate for phosphatidic acid formation (AbdelLatif, 1986; Berridge, 1987). The higher rate of phosphatidic acid formation in vitro in our assay system after energy depletion in vivo is therefore probably due to an increased activity of phospholipase C. The elevated levels of inositol phosphates and diacylglycerol will result in increased protein kinase activities and a change in cellular responses (Berridge, 1987). Hydrolysis of PIP, however, would result in a decreased rate of $\mathrm{PIP}_{2}$ formation (Bothmer et al., submitted). Because this was not the case, we conclude that the increased phospholipase $\mathrm{C}$ activity after acute cyanide-induced energy depletion is only directed against $\mathrm{PIP}_{2}$ and not against PIP. According to Ikeda et al. (1986), the concentration of phosphatidylinositol does not change after decapitation, which is a very drastic but simple model of brain ischaemia. This could explain the unaltered formation of PIP (out of phosphatidylinositol) in our assay system after energy depletion in vivo.

Chronic treatment with acetyl-I-carnitine was found to attenuate the cyanide-induced (dose $5.0 \mu \mathrm{g}$ ) behavioural deficit. This finding suggests that chronic treatment with acetyl-I-carnitine preserves neuronal function during a period of metabolic inhibition. A possible mechanism of action of acetyl-1-carnitine could be to enhance the utilization of alternative energy sources (lipid substrates and ketone bodies) during the 
hypoxic period (Aureli et al., 1990), thereby preserving neuronal function. This notion is supported by the results of a study in which the protective effect of l-carnitine in ammonia intoxication was evaluated (Ohtsuka and Griffith, 1991). It was suggested that l-carnitine could act by increasing the hepatic production of ketone bodies and thereby sustain energy needs during ammonia intoxication. Another, and more likely, explanation for the protective effect is that 1 -carnitine could have diminished the accumulation of membranedamaging and enzyme-inhibiting fatty acyl-CoAs, by shifting the equilibrium for carnitine palmitoyltransferase towards acyl-1-carnitines.

Chronic treatment with acetyl-l-carnitine did not attenuate the effect of cyanide on phosphoinositide metabolism. This indicates that the increased phospholipase $\mathrm{C}$ activity observed during an acute energy shortage in the rat brain is not primarily related to the cyanide-induced behavioural deficit. In addition, this finding suggests that the possible energy-enhancing property of acetyl-1-carnitine does not affect the highly energy-dependent metabolism of phosphatidylinositol in this model. We therefore assume that it is unlikely that acetyl-I-carnitine acted by increasing energy metabolism in the brain in this model. Besides the accumulation of diacylglycerol, free fatty acids also appear to accumulate in the rat brain during an acute energy shortage (lkeda et al., 1986). It was found recently that acetyl-l-carnitine could serve as a reservoir of activated acyl groups, which are involved in the reacylation of membrane phospholipids via the enzyme carnitine acyltransferase (Arduini et al., 1992). Thus, acetyl-l-carnitine could preserve neuronal function during an acute and short-lasting period of hypoxia by increasing the utilization of fatty acids as acylated derivatives by increasing the reservoir of activated acyl-groups. Such a mechanism of action is supported by the results of the study of Ohtsuka and Griffith (1991, see above).

In conclusion, the model developed in the present study allows the assessment of behaviour during a period of acute central histotoxic hypoxia. Treatment with cyanide disrupted the swimming behaviour of young rats for about 5 min post-injection; thereafter, the effects were no longer measurable. This behavioural deficit could be explained by a disturbed hippocampal phosphoinositide metabolism, as phospholipase $\mathrm{C}$ activity in the hippocampus was increased 1 min after injection of cyanide. Acetyl-1-carnitine, a nootropic drug, reversed the behavioural deficit but not the biochemical effect of hypoxia. This dissociation between behavioural and biochemical effects suggests that acetyl-l-carnitine probably enhances the metabolism of free fatty acids and thereby preserves neuronal function during a period of acute hypoxia. The model presented here can be used to study the acute effects (behavioural and biochemical) of drugs that are assumed to preserve neuronal function during energy low states.

\section{References}

Abdel-Latif, A.A., 1986, Calcium-mobilizing receptors, polyphosphoinositides, and the generation of second messengers, Pharmacol. Rev. 38, 227.

Abe, K., K. Kogure, H. Yamamoto, M. Imazawa, and K. Miyamoto, 1987, Mechanism of arachidonic acid liberation during ischemia in gerbil cerebral cortex, J. Neurochem. 48,503

Akhtar, R.A. and A.A. Abdel-Latif, 1980, Requirement for Ca2 ${ }^{+}$ ions in acetyl-choline stimulated phosphodiesteratic cleavage of phosphatidyl-myo-inositol 4,5-biphosphate in rabbit iris smooth muscle. Biochem. J. 192, 783.

Arduini, A., G. Mancinelli, G.L. Radatti, S. Dottori, F. Molajoni and R.R. Ramsay, 1992, Role of carnitine and carnitine palmitoyltransferase as integral components of the pathway for membrane phospholipid fatty acid turnover in intact human erythrocytes, $J$. Biol. Chem. 267, 12673.

Auer, R.N., T. Wieloch, Y. Olsson and B.K. Siesjö, 1984, The distribution of hypoglycemic brain damage, Acta Neuropathol. 64, 177.

Aureli, T., A. Michelli, R. Ricciolini, M. Enrica Di Cocca, M.T. Ramacci, L. Angeluci, O. Ghirardi and F. Conti, 1990, Aging brain: effect of acetyl-l-carnitine treatment on rat brain energy and phospholipid metabolism. A study by $31 \mathrm{P}$ and $1 \mathrm{H}$ NMR spectroscopy, Brain res. 526, 108.

Barnes, C.A., A.L. Markowska, D.K., Ingram, H. Kametani, E.L. Spangler, V.J. Lemken and D.S. Olton, 1990, Acetyl-I-carnitine 2: Effects on learning and memory performance of aged rats in simple and complex mazes, Neurobiol. Aging 11, 499.

Baughman, V.L., W.E. Hoffman, D.J. Miletich and R.F. Albrecht, 1990, Cerebrovascular and cerebral metabolic effects of N20 in unrestrained rats, Anesthesiology 73, 269.

Behroozi, K.R., R. Guttman, N. Gruener and H.I. Shuval, 1972 , Changes in motor activity of mice given sodium nitrite in drinking solution, Israel. J. Med. Sci. 8, 1007.

Bellei, M., D. Battelli, D.M. Guarriero, U. Muscatello, F. DiLisa, N. Siliprandi and V. Bobyleva-Guarriero, 1989, Changes in mitochondrial activity caused by ammonium salts and the protective effect of carnitine, Biochem. Biophys. Res. Commun. 158, 181.

Berridge, M.J., 1987, Inositol triphosphate and diacylglycerol: two interacting second messengers, Ann. Rev. Biochem. 56, 159.

Bothmer, J., M. Markerink and J. Jolles, 1990, Phosphatidic acid and polyphosphoinositide formation in a broken cell preparation from rat brain: effects of different incubation conditions, Neurochem. Int. 17, 27.

Brierly, J.B., A.W., Brown and C. Calverley, 1976, Cyanide intoxication in the rat: physiological and neuropathological aspects, J. Neurol. Neurosur. Psychiat. 39, 129.

Caprioli, A., O. Ghirardi, M.T. Ramacci and L. Angelucci, 1990, Age-dependent deficits in radial maze performance in the rat: effect of chronic treatment with acetyl-1-carnitine, Prog. Neuropsychopharm. Biol. Psychiat. 14, 359.

Costa, L.G., 1990, the phosphoinositide/protein kinase C system is a potential target for neurotoxicity, Pharmacol. Res. 22, 393.

Crane, P.D., L.D. Braun, E.M. Cornford, J.E. Cremer, J.M. Glass and W.H. Oldendorf, 1978, Dose-dependent reduction of glucose utilization by pentobarbital in rat brain, Stroke 9,12 .

De Ryck, M., 1990, Animal models of cerebral stroke: pharmacological protection of function, Europ. Neurol. 30, 21. 
D’Mello, G.D., 1986, Effects of sodium cyanide upon swimming performance in guinea-pigs and the conferment of protection by pretreatment with p-aminopropiophenone, Neurobehav. Toxicol. Tetratol. 8, 171.

Fritz, I.B., 1963, Carnitine and its role in fatty acid metabolism, Adv. Lip. Res. 1, 285.

Ghirardi, O., S. Milano, M.T. Ramacci and L. Angelucci, 1988, Effect of acetyl-l-carnitine chronic treatment on discrimination models in aged rats, Physiol. Behav. 44, 769.

Gibson, G.E., C.J. Pelmas and C. Peterson, 1983, Cholinergic drugs and 4-aminopyridine alter hypoxic-induced behavioral deficits, Pharmacol Biochem. Behav. 18, 909.

Gibson, G.E. and Peterson, 1981, Aging decreases metabolism and the release and synthesis of acetylcholine, J. Neurochem. 37, 978.

Hathway, D.E., 1984, Molecular aspects of toxicology (The Royal Society of Chemistry, London) p. 84.

Hoyer, S. and C. Krier, 1986, Ischemia and the aging brain. Studies on glucose and energy metabolism in rat cerebral cortex, Neurobiol. Aging 7, 23.

Ikeda, M., S. Yoshida, R. Busto, M. Santiso and M.D. Ginsberg, 1986. Polyphosphoinositides as a probable source of brain free fatty acids accumulated at the inset of ischemia, J. Neurochem. $47,123$.

Jolles, J., L.H. Schrama and Gispen, W.H., 1981, Calcium-dependent turnover of brain phosphoinositides in vitro after prelabeling in vivo, Biochim. Biophys. Acta 666, 90.

MacMillan, V.H., 1989, Cerbral energy metabolism in cyanide encephalopathy, J. Cerebr. Blood Flow Metabol. 9, 156.

Morris, R.G.M., 1981, Spatial localization does not require the presence of local cues, Learn. Motiv. 12, 239.

Morris, R.G.M., F. Schenk, F. Tweedie and L.E. Jarrard, 1990, Ibotenate lesions of hippocampus and/or subiculum: dissociating components of allocentric spatial learning, Europ. J. Neurosci. 2. 1016.

Ohtsuka, Y. and Griffith, O.W., 1991, 1-Carnitine protection in ammonia intoxication, Biochem. Pharmacol. 41, 1957.

Paxinos, G. and Watson, C., 1986, The Rat Brain in Stereotaxic Coordinates (2nd edn.) (Academic Press, Sydney).

Peruche, B., B. Ahlmeyer, H. Brungs and J. Krieglstein, 1990, Cultured neurons for testing antihypoxic drug effects, J. Pharmacol. Meth. 23, 63 .

Schoeder, F., 1984, Role of membrane lipid asymmetry in aging, Neurobiol. Aging 5, 323.

Siliprandi, N., D. Siliprandi and M. Ciman, 1965. Stimulation of oxidation of mitochondrial fatty acids and of acetate by acetylcarnitine, Biochem. J. 96, 777.

Way, J.L., 1984, Cyanide intoxication and its mechanisms of antagonism, Ann. Rev. Pharmacol. Toxicol. 24, 451. 